Louisiana State University

LSU Digital Commons

Faculty Publications

School of Veterinary Medicine

2021

\title{
Experimental Re-Infected Cats Do Not Transmit Sars-Cov-2
}

N N. Gaudreault

jricht@ksu.edu

M Carossino

I Morozov

J D. Trujillo

N N. Gaudreault

See next page for additional authors

Follow this and additional works at: https://digitalcommons.Isu.edu/vetmed_pubs

\section{Recommended Citation}

Gaudreault, N. N., Carossino, M., Morozov, I., Trujillo, J. D., Gaudreault, N. N., Madden, D. W., Cool, K., Artiaga, B. L., McDowell, C., Bold, D., Balaraman, V., Kwon, T., Ma, W. J., Henningson, J., Wilson, D. W., Wilson, W. C., Balasuriya, U. C., Garcia-Sastre, A., \& Richt, J. A. (2021). Experimental Re-Infected Cats Do Not Transmit Sars-Cov-2. Emerging Microbes \& Infections, 10 (1), 638-650. https://doi.org/10.1080/ 22221751.2021 .1902753

This Article is brought to you for free and open access by the School of Veterinary Medicine at LSU Digital Commons. It has been accepted for inclusion in Faculty Publications by an authorized administrator of LSU Digital Commons. For more information, please contact ir@lsu.edu. 


\section{Authors}

N N. Gaudreault, M Carossino, I Morozov, J D. Trujillo, N N. Gaudreault, D W. Madden, K Cool, B L. Artiaga, C McDowell, D Bold, V Balaraman, T Kwon, W J. Ma, J Henningson, D W. Wilson, W C. Wilson, U C.

Balasuriya, A Garcia-Sastre, and J A. Richt 


\section{Experimental re-infected cats do not transmit SARS-CoV-2}

Natasha N. Gaudreault, Mariano Carossino, Igor Morozov, Jessie D. Trujillo, David A. Meekins, Daniel W. Madden, Konner Cool, Bianca Libanori Artiaga, Chester McDowell, Dashzeveg Bold, Velmurugan Balaraman, Taeyong Kwon, Wenjun Ma, Jamie Henningson, Dennis W. Wilson, William C. Wilson, Udeni B. R. Balasuriya, Adolfo García-Sastre \& Juergen A. Richt

To cite this article: Natasha N. Gaudreault, Mariano Carossino, Igor Morozov, Jessie D. Trujillo, David A. Meekins, Daniel W. Madden, Konner Cool, Bianca Libanori Artiaga, Chester McDowell, Dashzeveg Bold, Velmurugan Balaraman, Taeyong Kwon, Wenjun Ma, Jamie Henningson, Dennis W. Wilson, William C. Wilson, Udeni B. R. Balasuriya, Adolfo García-Sastre \& Juergen A. Richt (2021) Experimental re-infected cats do not transmit SARS-CoV-2, Emerging Microbes \& Infections, 10:1, 638-650, DOI: 10.1080/22221751.2021.1902753

To link to this article: https://doi.org/10.1080/22221751.2021.1902753 (c) 2021 The Author(s). Published by Informa
UK Limited, trading as Taylor \& Francis Group.

\footnotetext{
曲 Published online: 02 Apr 2021.
}

LII Article views: 2334
View Crossmark data $\nearrow$

\footnotetext{
rarticle views: 2334
}

$\bigodot_{\text {CrossMark }}$ View Crossmark data $₫$

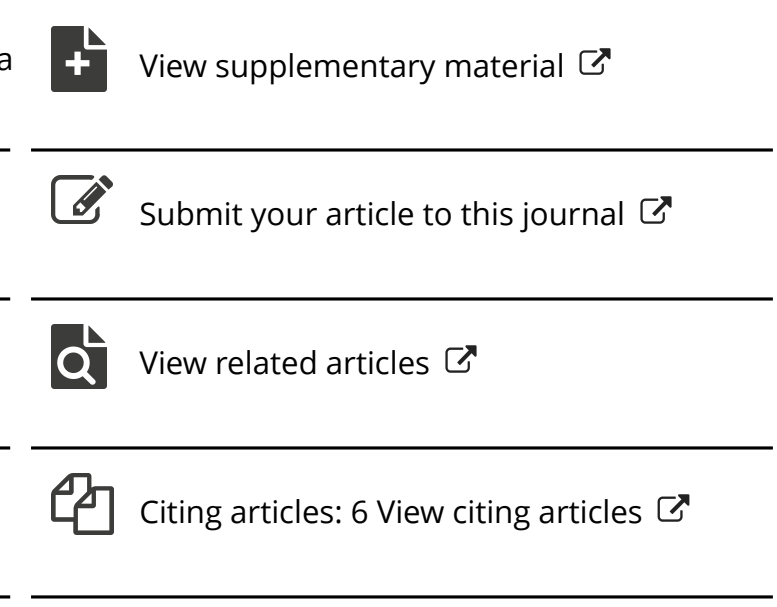




\title{
Experimental re-infected cats do not transmit SARS-CoV-2
}

\begin{abstract}
Natasha N. Gaudreault ${ }^{a}$, Mariano Carossino ${ }^{b}$, Igor Morozov ${ }^{a}$, Jessie D. Trujillo ${ }^{a}$, David A. Meekins ${ }^{a}$, Daniel W. Madden ${ }^{\mathrm{a}}$, Konner Cool ${ }^{\mathrm{a}}$, Bianca Libanori Artiaga ${ }^{\mathrm{a}}$, Chester McDowell ${ }^{\mathrm{a}}$, Dashzeveg Bold ${ }^{\mathrm{a}}$, Velmurugan Balaraman (ib ${ }^{a}$, Taeyong Kwon ${ }^{a}$, Wenjun Ma a, ${ }^{a}$, Jamie Henningson ${ }^{a}$, Dennis W. Wilson $^{d}$, William C. Wilson (1) ${ }^{e}$, Udeni B. R. Balasuriya ${ }^{b}$, Adolfo García-Sastre ${ }^{f, g, h, i}$ and Juergen A. Richt (1)

aDepartment of Diagnostic Medicine/Pathobiology, College of Veterinary Medicine, Kansas State University, Manhattan, KS, USA; b Louisiana Animal Disease Diagnostic Laboratory and Department of Pathobiological Sciences, School of Veterinary Medicine, Louisiana State University, Baton Rouge, LA, USA; 'Department of Veterinary Pathobiology and Department of Molecular Microbiology and Immunology, University of Missouri, Columbia, MO, USA; ${ }^{\mathrm{d}}$ Department of Pathology, Microbiology and Immunology, School of Veterinary Medicine, University of California-Davis, Davis, CA, USA; ${ }^{\circ}$ Arthropod Borne Animal Disease Research Unit, Agricultural Research Service, United States Department of Agriculture, Manhattan, KS, USA; 'Department of Microbiology, Icahn School of Medicine at Mount Sinai, New York, NY, USA; ${ }^{9}$ Global Health and Emerging Pathogens Institute, Icahn School of Medicine at Mount Sinai, New York, NY, USA; ${ }^{h}$ Department of Medicine, Division of Infectious Diseases, Icahn School of Medicine at Mount Sinai, New York, NY, USA; 'The Tisch Cancer Institute, Icahn School of Medicine at Mount Sinai, New York, NY, USA
\end{abstract}

\section{ABSTRACT}

SARS-CoV-2 is the causative agent of COVID-19 and responsible for the current global pandemic. We and others have previously demonstrated that cats are susceptible to SARS-CoV-2 infection and can efficiently transmit the virus to naïve cats. Here, we address whether cats previously exposed to SARS-CoV-2 can be re-infected with SARS-CoV-2. In two independent studies, SARS-CoV-2-infected cats were re-challenged with SARS-CoV-2 at 21 days post primary challenge (DPC) and necropsies performed at 4,7 and 14 days post-secondary challenge (DP2C). Sentinels were comingled with the re-challenged cats at $1 \mathrm{DP} 2 \mathrm{C}$. Clinical signs were recorded, and nasal, oropharyngeal, and rectal swabs, blood, and serum were collected and tissues examined for histologic lesions. Viral RNA was transiently shed via the nasal, oropharyngeal and rectal cavities of the re-challenged cats. Viral RNA was detected in various tissues of re-challenged cats euthanized at 4 DP2C, mainly in the upper respiratory tract and lymphoid tissues, but less frequently and at lower levels in the lower respiratory tract when compared to primary SARS-CoV-2 challenged cats at 4 DPC. Viral RNA and antigen detected in the respiratory tract of the primary SARS-CoV-2 infected cats at early DPCs were absent in the re-challenged cats. Naïve sentinels co-housed with the re-challenged cats did not shed virus or seroconvert. Together, our results indicate that cats previously infected with SARS-CoV-2 can be experimentally reinfected with SARS-CoV-2; however, the levels of virus shed was insufficient for transmission to co-housed naïve sentinels. We conclude that SARS-CoV-2 infection in cats induces immune responses that provide partial, nonsterilizing immune protection against re-infection.

ARTICLE HISTORY Received 18 January 2021; Revised 9 March 2021; Accepted 10 March 2021

KEYWORDS SARS-CoV-2; COVID-19; re-infection; transmission; cats

\section{Introduction}

Severe Acute Respiratory Syndrome Coronavirus 2 (SARS-CoV-2) is the causative agent of Coronavirus Disease 2019 (COVID-19), first identified in Wuhan China in late 2019 and responsible for the ongoing global pandemic [1]. SARS-CoV-2 is highly transmissible and capable of causing severe disease in humans. Furthermore, there have been multiple cases reported of transmission from COVID-19 patients to animals including domestic cats, large cats, dogs, ferrets, and mink in China, South America, the United States and Europe ([2-9]; summary of US cases: https://www. aphis.usda.gov/aphis/ourfocus/animalhealth/SA_One Health/sars-cov-2-animals-us). Evidence supporting reverse zoonosis of mink infecting humans has also been reported [10]. Understanding SARS-CoV-2 susceptibility, transmission and re-infection in companion animals and livestock species that are frequently in close proximity with humans is important for assessing risk and implementing mitigation strategies to stop virus spread in order to maintain public health as well as food and economic security [11].

Recently, we and others have demonstrated that domestic cats are susceptible to SARS-CoV-2 by experimental infection and can readily transmit the virus to naïve cats [12-15]. Cats inoculated via natural routes of exposure can be infected and shed the virus from nasal, oral and rectal cavities starting from 1 up to 14 days with peak virus shedding occurring within

CONTACT Juergen A. Richt 0 jricht@ksu.edu

(4) Supplemental data for this article can be accessed at https://doi.org/10.1080/22221751.2021.1902753

This article has been republished with minor changes. These changes do not impact the academic content of the article.

() 2021 The Author(s). Published by Informa UK Limited, trading as Taylor \& Francis Group.

This is an Open Access article distributed under the terms of the Creative Commons Attribution License (http://creativecommons.org/licenses/by/4.0/), which permits unrestricted use, distribution, and reproduction in any medium, provided the original work is properly cited. 
the first 7 days after infection [12-15]. Together these studies show that cats ranging from 4 months up to 8 years of age remain asymptomatic with no significant gross pathological changes, and mild to moderate histological alterations associated mainly with the upper respiratory tract tissues [12-15]. In contrast, mortality and severe histological lesions in tissues of the upper and lower respiratory tract were observed for juvenile cats younger than 4 months of age infected with SARS-CoV-2 [13]. Cats also develop virus-specific and neutralizing antibody responses to SARS-CoV-2 [7,12-17]. A more detailed understanding of the role that these immune responses play in protection from re-exposure to SARS-CoV-2 is imperative.

Here, we present a detailed investigation on SARSCoV-2 re-infection of sub-adult domestic cats at 21 DPC in two independent studies. In the second reinfection study, two sentinel contact cats were introduced at $1 \mathrm{DP} 2 \mathrm{C}$ to determine if transmission to naive animals could occur after re-infection. Results of the clinical course of SARS-CoV-2 re-infection, viral shedding and transmission in cats previously infected with SARS-CoV-2 are presented.

\section{Materials and methods}

\section{Cells and virus}

Vero E6 cells (ATCC CRL-1586 ${ }^{\mathrm{TM}}$, American Type Culture Collection, Manassas, VA, USA) were used for virus propagation and titration. Cells were cultured in Dulbecco's Modified Eagle's Medium (DMEM, Corning, New York, NY, USA), supplemented with 5\% fetal bovine serum (FBS, R\&D Systems, Minneapolis, MN, USA) and antibiotics/antimycotics (ThermoFisher Scientific, Waltham, MA, USA), and maintained at $37^{\circ}$ $\mathrm{C}$ under a $5 \% \mathrm{CO}_{2}$ atmosphere. The SARS-CoV-2 USA-WA1/2020 strain was acquired from BEI Resources (Manassas, VA, USA) and passaged three times in Vero E6 cells to establish a stock virus $\left(1 \times 10^{6} \mathrm{TCID}_{50} / \mathrm{mL}\right)$ for inoculation of animals. This stock virus was sequenced by next generation sequencing (NGS) using the Illumina MiSeq and its consensus sequence was found to be homologous to the original USA-WA1/ 2020 strain (GenBank accession: MN985325.1). To determine infectious virus titer, 10-fold serial dilutions were performed on Vero E6 cells. The presence of cytopathic effects (CPE) after 96 hours incubation was used to calculate the $50 \%$ tissue culture infective dose $\left(\mathrm{TCID}_{50}\right) / \mathrm{mL}$ using the Spearman-Karber method.

\section{Animals and experimental design}

\section{Ethics statement for use of animals}

All animal studies and experiments were approved and performed under the Kansas State University (KSU) Institutional Biosafety Committee (IBC,
Protocol \#1460) and the Institutional Animal Care and Use Committee (IACUC, Protocol \#4390) in compliance with the Animal Welfare Act. All animal and laboratory work were performed in biosafety level-3 + and -3Ag facilities in the Biosecurity Research Institute at KSU in Manhattan, KS, USA.

\section{SARS-CoV-2 re-infection of animals}

Two independent re-infection studies were performed in sub-adult domestic cats 5 or 7 months of age, respectively. The cats were antibody profile defined/ specific pathogen free (APD/SPF) animals with no detectable antibody titers to feline herpesvirus, feline calicivirus, feline panleukopenia virus, feline coronaviruses, feline immunodeficiency virus, Chlamydia felis and Toxoplasma gondii, and obtained from Marshall BioResources (North Rose, New York, USA). Animal identification numbers and treatment assignments for each study are summarized in Table 1. In the first study, three cats from a previous SARSCoV-2 challenge and transmission study [12], including one principal and two sentinel cats, were re-challenged with SARS-CoV-2 at 21 days post primary challenge (DPC) and sacrificed at 4 days post second challenge (DP2C). The same dose as used for primary challenge, namely $2 \mathrm{~mL}$ of $10^{6} \mathrm{TCID}_{50}$ SARS-CoV-2 was administered to each cat both intranasal $(0.5 \mathrm{~mL}$ per nostril) and per os $(1 \mathrm{~mL})$ simultaneously.

In the second study, a total of six principal cats, two groups of three, were challenged with SARS-CoV-2 with the same dose and route as detailed in the first study. At 1 DPC, two sentinel contact cats were added, one per group of challenged cats. Post-mortem examinations were performed on two principal animals at 4 DPC and one principal animal at 21 DPC. At 21 DPC, five cats including the remaining three principals and the two sentinels were re-challenged with SARS-CoV-2 using the same dose and route as in the primary challenge. At $1 \mathrm{DP} 2 \mathrm{C}$, two new naïve

Table 1. Animals and treatment assignments.

\begin{tabular}{|c|c|c|c|c|}
\hline \multirow[b]{2}{*}{ Cat ID } & \multicolumn{2}{|c|}{ Primary challenge } & \multicolumn{2}{|c|}{ Re-challenge } \\
\hline & Treatment & Necropsy & Treatment & Necropsy \\
\hline \multicolumn{5}{|c|}{ Study 1 (5-month-old domestic cats) } \\
\hline 328 & Principal & na & principal (21 DPC) & $4 \mathrm{DP} 2 \mathrm{C}$ \\
\hline 272 & sentinel (1 DPC) & na & principal (21 DPC) & $4 \mathrm{DP} 2 \mathrm{C}$ \\
\hline 903 & sentinel (1 DPC) & na & principal (21 DPC) & $4 \mathrm{DP} 2 \mathrm{C}$ \\
\hline \multicolumn{5}{|c|}{ Study 2 (7-month-old domestic cats) } \\
\hline 305 & Principal & $4 \mathrm{DPC}$ & na & na \\
\hline 526 & Principal & $4 \mathrm{DPC}$ & na & na \\
\hline 160 & Principal & $21 \mathrm{DPC}$ & na & na \\
\hline 135 & Principal & na & principal (21 DPC) & $4 \mathrm{DP} 2 \mathrm{C}$ \\
\hline 590 & Principal & na & principal (21 DPC) & $4 \mathrm{DP} 2 \mathrm{C}$ \\
\hline 247 & Principal & na & principal (21 DPC) & $7 \mathrm{DP} 2 \mathrm{C}$ \\
\hline 119 & sentinel (1 DPC) & na & principal (21 DPC) & $7 \mathrm{DP} 2 \mathrm{C}$ \\
\hline 127 & sentinel (1 DPC) & na & principal (21 DPC) & 14 DP2C \\
\hline 280 & na & na & sentinel (1 DP2C) & $14 \mathrm{DP} 2 \mathrm{C}$ \\
\hline 620 & na & na & sentinel (1 DP2C) & 14 DP2C \\
\hline
\end{tabular}




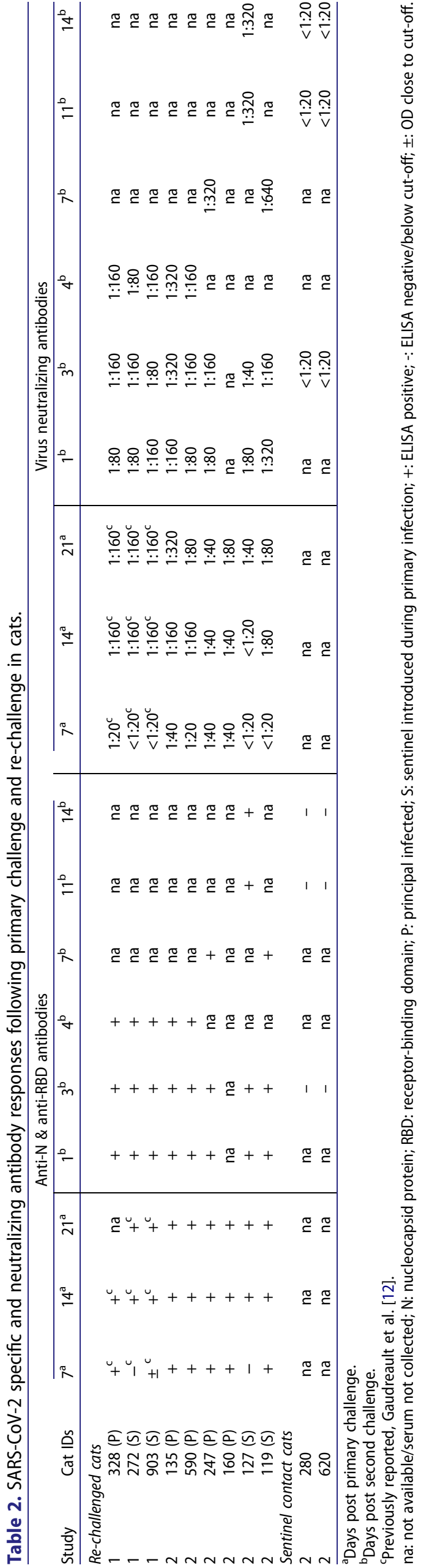

sentinel cats were introduced. Two re-challenged animals each were euthanized and post-mortem examinations performed at 4 and $7 \mathrm{DP} 2 \mathrm{C}$, respectively. The remaining re-challenged cat and the two sentinels were euthanized and post-mortem examinations performed at 14 DP2C.

\section{Clinical evaluations and sample collection}

Cats were observed daily for clinical signs, as described previously [12]. Weights of all cats were recorded on bleed days. Blood and serum were collected from all primary inoculated and sentinel cats at $0,1,3,4,7$, 14 and $21 \mathrm{DPC}$, and the re-infected and sentinels at $0,1,3,4,7,11$ and $14 \mathrm{DP} 2 \mathrm{C}$ via venipuncture of the cephalic vein under anaesthesia or during terminal bleeding by cardiac puncture. Nasal, oropharyngeal and rectal swabs were collected at $0,1,3,4,5,7,10$, 14,18 and 21 DPC, and at $0,1,3,4,5,7,8,11$ and $14 \mathrm{DP} 2 \mathrm{C}$ in $2 \mathrm{~mL}$ of DMEM (Corning,) with antibiotics/antimycotic (ThermoFisher). Swabs were vortexed and supernatant aliquoted directly into cryovials or into RLT buffer (Qiagen, Germantown, $\mathrm{MD}$, USA) and stored at $-80^{\circ} \mathrm{C}$ until further analysis.

A full post-mortem examination was performed for each cat and gross changes (if any) were recorded. Tissues were collected either in 10\% neutral-buffered formalin (Fisher Scientific, Waltham, MA, USA), or as fresh tissues which were then frozen at $-80{ }^{\circ} \mathrm{C}$. Tissues were collected from the upper respiratory tract (URT) and lower respiratory tract (LRT), central nervous system (brain and cerebral spinal fluid [CSF]), gastrointestinal tract (GIT) as well as accessory organs. Lung lobes were evaluated based on gross pathology and then bronchoalveolar lavage fluid (BALF) was collected. The lungs were removed in toto including the trachea. The main bronchi were collected at the level of the bifurcation and at the entry point into the lung lobe. Nasal wash and urine were also collected during post-mortem examination and stored at $-80^{\circ}$ $\mathrm{C}$ until analysed. Fresh frozen tissue homogenates were prepared as described previously [12] and the supernatant retained for RNA extraction and quantitative reverse transcription real-time PCR (RT-qPCR).

\section{RNA extraction and quantitative real-time reverse transcription PCR (RT-qPCR)}

SARS-CoV-2-specific RNA was detected using a quantitative reverse transcription real-time PCR (RTqPCR) assay as previously described [12]. Briefly, tissue homogenates and swab samples in DMEM, blood, CSF, BALF, and urine, were mixed with an equal volume of RLT RNA stabilization/lysis buffer

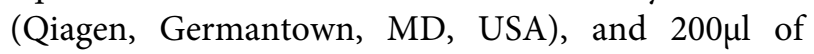
sample lysate was then used for extraction using a magnetic bead-based nucleic acid extraction kit 
(Gene-Reach USA, Lexington, MA) on an automated Taco $^{\text {TM }}$ mini nucleic acid extraction system (GeneReach) as described previously [12]. Positive (IDT, IA, USA; 2019-nCoV_N_Positive Control, diluted 1:100 in RLT) and negative extraction controls were employed.

Quantification of SARS-CoV-2 RNA was performed as previously described [12] using the N2 SARS-CoV-2 primer and probe set in a RT-qPCR protocol established by the CDC for the detection of SARS-CoV-2 nucleocapsid protein (N)-specific RNA [18]. A 10-point standard curve of quantitated viral RNA (USA-WA1/2020 isolate) was used to quantify RNA copy number. A positive Ct cut-off of 40 cycles was used and any signal after the 40 cycle threshold was considered as non-specific or not significant. Each sample was run in duplicate reactions and only samples with 2 out of 2 positive RT-qPCR reactions are presented. Samples with 1 of 2 RT-qPCR positive reactions were treated as suspect and indicated by an asterisk in the presented figures. Data are shown as the mean of the calculated $\mathrm{N}$ gene copy number per $\mathrm{mL}$ of liquid sample or per $\mathrm{mg}$ of a $20 \%$ tissue homogenate.

\section{Virus isolation}

Select swab and tissue homogenate samples from rechallenged cats were tested for viable virus by culture on Vero E6 cells. Virus isolation was performed by culturing $400 \mu \mathrm{L}$ of filtered sample on Vero E6 cells and monitoring for CPE for up to 5 days post inoculation. Based on our test results of samples from primary infected cats, virus isolation was only performed on samples with $\geq 10^{6}$ RNA copy number per $\mathrm{mL}$, as this was our approximate limit of detection (LOD) for viable virus using this method.

\section{Histopathology}

Tissue samples from the nasal cavity [rostral, middle and deep turbinates following decalcification with Immunocal $^{\mathrm{TM}}$ Decalcifier [StatLab, McKinney, TX] for 4-7 days at room temperature], trachea, and lungs as well as various other extrapulmonary tissues (liver, spleen, kidneys, heart, pancreas, gastrointestinal tract [stomach, small intestine including Peyer's patches and colon], cerebrum [including olfactory bulb], tonsils and numerous lymph nodes) were routinely processed and embedded in paraffin. Four-micron tissue sections were stained with haematoxylin and eosin following standard procedures. Several independent veterinary pathologists (blinded to the treatment groups) examined the slides.

\section{SARS-CoV-2-specific RNAscope in situ hybridization (RNAscope ISH)}

RNAscope ISH was performed as previously described [12] using an anti-sense probe targeting the spike protein gene ( $\mathrm{S}$; nucleotide sequence: 21,563-25,384) of SARS-CoV-2, USA-WA1/2020 isolate (GenBank accession number MN985325.1) which was designed by Advanced Cell Diagnostics ([ACD], Newark, CA, USA) and used as previously described [19]. Four-micron sections of formalin-fixed paraffin-embedded tissues were subjected to in situ hybridization. Lung sections from a SARS-CoV-2infected hamster were used as positive assay controls.

\section{SARS-CoV-2-specific immunohistochemistry (IHC)}

IHC was performed as previously described [12] on four-micron sections of formalin-fixed paraffinembedded tissue mounted on positively charged Superfrost Plus slides and subjected to IHC using a SARS-CoV-2-specific anti-nucleocapsid rabbit polyclonal antibody (3A, developed by our laboratory) with the method previously described [19]. Lung sections from a SARS-CoV-2-infected hamster were used as positive assay controls.

\section{Virus neutralizing antibodies}

Virus neutralizing antibodies in sera were determined using microneutralization assay as previously described [12]. Briefly, heat inactivated serum samples were subjected to two-fold serial dilutions starting at $1: 20$, and tested in duplicate. Then, $100 \mathrm{TCID}_{50}$ of SARS-CoV-2 virus in DMEM culture media was added 1:1 to the sera dilutions and incubated for $1 \mathrm{~h}$ at $37^{\circ} \mathrm{C}$, then cultured on Vero E6 cells in 96-well plates. The corresponding SARS-CoV-2-negative cat sera, virus only and media only controls were also included in the assay. The neutralizing antibody titer was recorded as the highest serum dilution at which at least $50 \%$ of wells showed virus neutralization based on the appearance of CPE observed under a microscope at $72 \mathrm{~h}$ post infection.

\section{Detection of SARS-CoV-2 antibodies by indirect ELISA}

To detect SARS-CoV-2 antibodies in sera, indirect ELISAs were performed with the recombinant viral proteins, nucleoprotein $(\mathrm{N})$ and the receptor-binding domain (RBD), as previously described [12]. Briefly, wells were coated with $100 \mathrm{ng}$ of the respective recombinant protein and serum samples were pre-diluted 1:400 for the assay. The cut-off for a sample being called positive was determined as follows: Average OD of negative serum $+3 \times$ standard deviation. Every read out above this cut-off was considered positive. 


\section{Results}

\section{Primary infected cats shed SARS-CoV-2, develop histologic lesions in the respiratory tract, and seroconvert while remaining clinically asymptomatic}

A similar study design was used for the primary cat infections as in our previous study evaluating primary infection and transmission in cats [12]; it consisted of six principal cats inoculated with SARS-CoV-2 and two sentinel contact cats introduced at 1 DPC (Figure 1). At 4 and $21 \mathrm{DPC}$, two and one of the principal infected cats were necropsied, respectively, to characterize primary infection and histological changes at these DPC, prior to re-infection of the five remaining animals at 21 DPC. Similar to our previous study [12], primary SARS-CoV-2 challenged cats shed virus from nasal, oral and rectal cavities and efficiently transmitted the virus to the naïve sentinels (Figure 2(a-c)). Viral RNA was found in multiple tissues of the two principal infected cats euthanized at 4 DPC, including the URT, LRT, GIT, lymphatic organs, heart and olfactory bulb (Figure 3). Histologic lesions were restricted to the upper respiratory tract and the bronchial tree as previously described [12]. Within the nasal cavity, there was evidence of neutrophilic rhinitis of variable intensity with numerous neutrophils infiltrating the lamina propria, transmigrating through the lining epithelium, and accumulating in the lumen along with cellular debris (Figure 4). The respiratory epithelium showed occasional sloughing (erosion) and attenuation. Seromucinous nasal glands were largely spared of histologic changes, with only rare glands within inflamed areas containing few luminal neutrophils or cell debris. SARS-CoV-2 antigen and viral RNA were detected within individual or clusters of squamous (rostral turbinates) and respiratory epithelial cells (intermediate and deep turbinates) via IHC and ISH. Even though the olfactory neuroepithelium was histologically unremarkable, viral antigen and RNA were segmentally detected (Figure 4). Lesions in the trachea and bronchial tree were mild, characterized by multifocal lymphohistiocytic and neutrophilic tracheobronchoadenitis with necrosis of the glandular epithelium and intralesional SARS-CoV-2 antigen and RNA as previously described (Figure 4; 12). At 21 DPC, viral shedding had subsided in both principal and contact primary infected animals, except for a single RNA positive oropharyngeal swab detected from one of the principal infected cats (Figure 2(b)). Limited viral RNA was detected in tissues of the URT, lymphatic organs and olfactory bulb, but not in the nasal wash, BALF, lung or digestive tract tissues of the principal infected cat euthanized at 21 DPC (Figure 3); virus isolation was not performed on these specific samples since RNA copy number was below the limit of detection for our virus isolation assay. All cats including principal and sentinel primary infected animals had detectable virus-specific and virus neutralizing antibodies by $21 \mathrm{DPC} / 0 \mathrm{DP} 2 \mathrm{C}$ (Table 2). At this time point, the intense neutrophilic rhinitis noted at 4 DPC was replaced by multifocal lymphoid aggregates in the lamina propria with only rare and localized areas of minimal neutrophilic inflammation. The respiratory mucosa and olfactory neuroepithelium were unremarkable and no viral antigen or RNA were detected within the nasal cavity at this timepoint (Figure 4). In the trachea and bronchi, there was no evidence of damage to tracheal and bronchial glands as noted at $4 \mathrm{DPC}$, with no viral antigen or RNA detected. Tracheal glands were only separated by mild numbers of lymphocytes and plasma cells, and peribronchial lymphoid aggregates were noted along the bronchial tree (Figure 4). Finally, no lesions were a

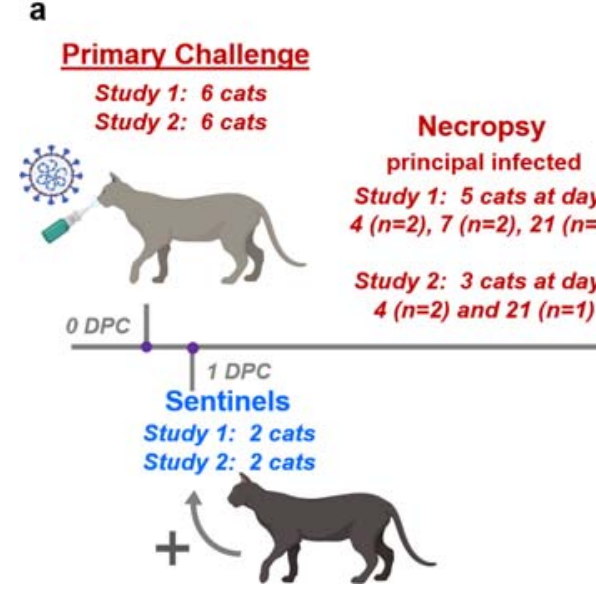

b
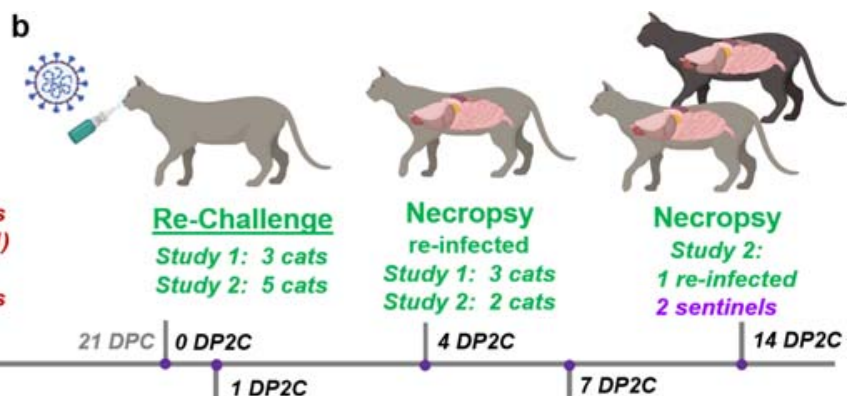

$1 D P 2 C$
Sentinels

Study 2: 2 cats
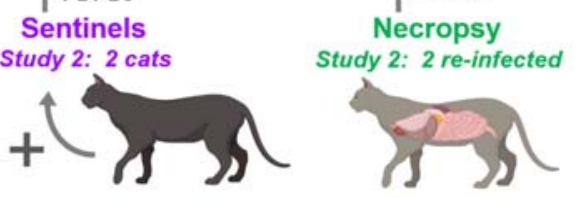

Figure 1. Re-infection study design. (a) In each of 2 studies, 6 cats were inoculated with SARS-CoV- 2 and 2 sentinel contact cats were introduced at 1 day post primary challenge (DPC). Necropsy was performed on principal infected cats at 4, 7 and 21 DPC. (b) At 21 DPC, cats were re-challenged with SARS-CoV-2 at the same dose as used for primary challenge, and 2 sentinels introduced at day 1 post second challenge (DP2C). Necropsy of principal re-infected cats were performed at 4, 7 and 14 DP2C, and of the sentinels at 14 PD2C. 
a

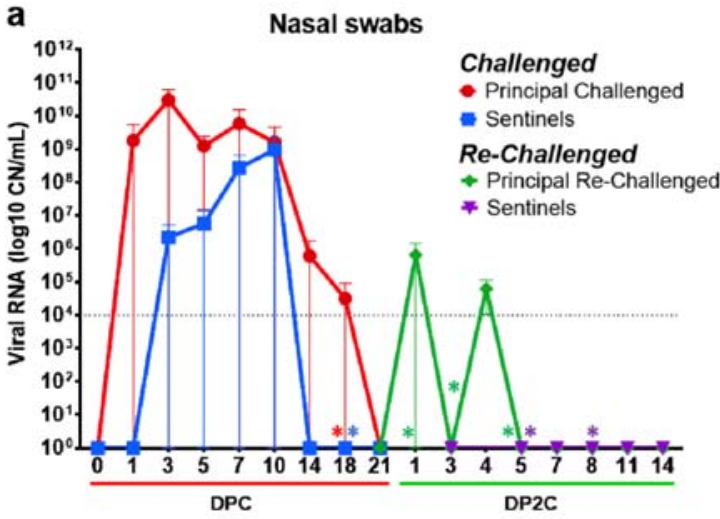

C

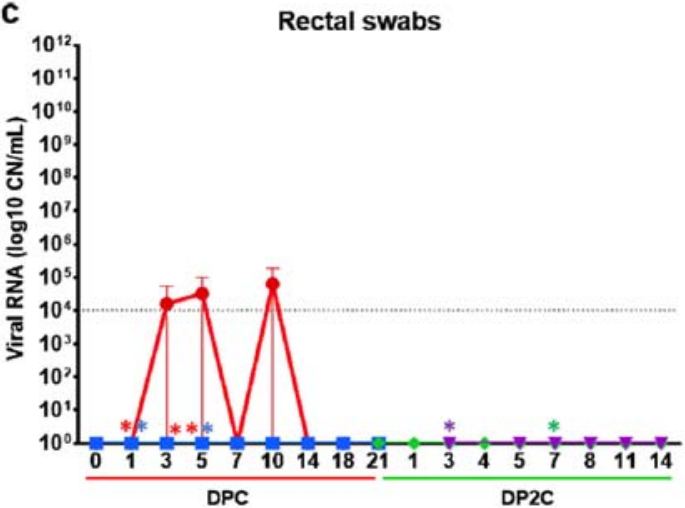

b

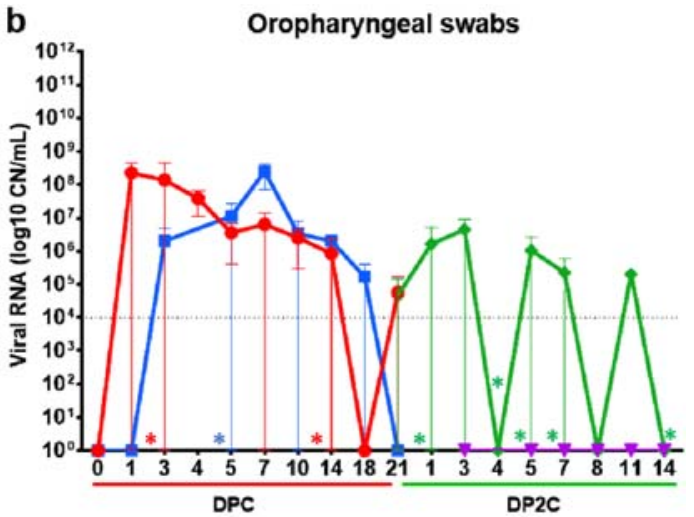

d

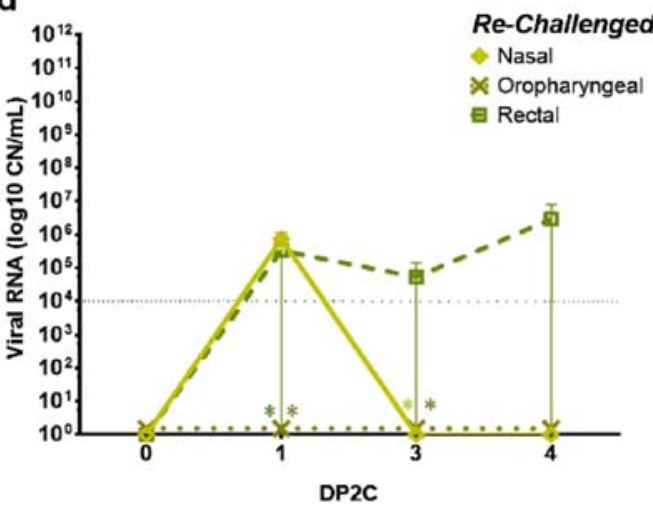

Figure 2. Viral shedding from SARS-CoV-2 infected and re-infected cats. RT-qPCR was performed on nasal (a), oropharyngeal (b) and rectal (c) swabs collected from cats at the indicated days following primary challenge (DPC) and re-challenge (DP2C) from the second re-infection study. Results represent all cats that were swabbed and tested at $0,1,3,5,7,10,14,18$ and 21 DPC, and at 0, 1 , $3,5,7,8,11$ and 14 DP2C. Results at 4 DPC and 4 DP2C are representative of only the 2 necropsied cats that were swabbed and tested on these days. (d) Nasal, oropharyngeal and rectal swabs collected from the 3 re-challenged cats from the first re-infection study. Mean and standard deviation of viral RNA copy number $(\mathrm{CN})$ per $\mathrm{mL}$ based on the nucleocapsid gene are shown. Asterisks $\left(^{*}\right)$ indicate samples with 1 out of 2 of the RT-qPCR reactions below the limit of detection (LOD), indicated by the dotted line.

identified in extrapulmonary tissues other than lymphoid hyperplasia within lymphoid organs.

\section{Re-infection of cats with SARS-CoV-2 leads to asymptomatic and limited viral shedding}

At 21 DPC/0 DP2C, three cats from the first study and five cats of the second study were re-challenged with SARS-CoV-2 (Figure 1). In the first study, viral shedding was detected from nasal swabs at $1 \mathrm{DP} 2 \mathrm{C}$ and from rectal swabs at 1-4 DP2C, but not from oropharyngeal swabs of the three re-challenged cats (Figure 2(d)). Rechallenged cats from the second study shed viral RNA intermittently from the nasal cavity at 1 through 4 DP2C and similarly from the oropharyngeal cavity at 1 through 11 DP2C; however, no viral RNA was detected from rectal swabs after re-challenge in study 2 (Figure 2 $(\mathrm{a}-\mathrm{c}))$. No viable virus was detected in the swabs of reinfected cats from either study.

In addition, viral RNA was detected in the nasal wash, URT and GIT tissues of re-infected cats euthanized at 4 and 7 DP2C (Figure 3(a,d,f)). Limited viral RNA was detected in the LRT of some animals and some LRT tissues of cats euthanized after re-infection at 4 and 7 DP2C, including the bronchi and three of the seven lung sections collected (Figure 3(e)). Viral RNA was also found in the lymphatic tissues, heart and olfactory bulb of the re-infected cats at 4 and 7 DP2C, and the kidney of one animal at 4 DP2C, at similar levels as detected in the cats during primary infection (Figure 3). CSF from one of the re-challenged cats euthanized at $4 \mathrm{DP} 2 \mathrm{C}$ was also positive (Figure 3(c)). By 14 DP2C, viral RNA was only detected in the tonsil of the remaining principal rechallenged cat. No viral RNA was detected from the blood of primary SARS-CoV-2 challenged or re-challenged cats (data not shown).

No significant clinical symptoms or weight changes were observed for any of the primary SARS-CoV-2 challenged or re-challenged cats during the course of these studies. On the day of re-challenge, all cats had virus neutralizing antibodies with titers ranging from 1:40 to $1: 320$ (Table 2). A statistically significant increase in neutralizing antibody titers was observed following re-infection at 7 DP2C, suggestive of an anamnestic immune response after re-infection with SARS-CoV-2 (Table 2 and Figure 5).

Histologic changes within the upper and lower respiratory tracts, as well as extrapulmonary tissues were evaluated in re-infected cats. While there was evidence 

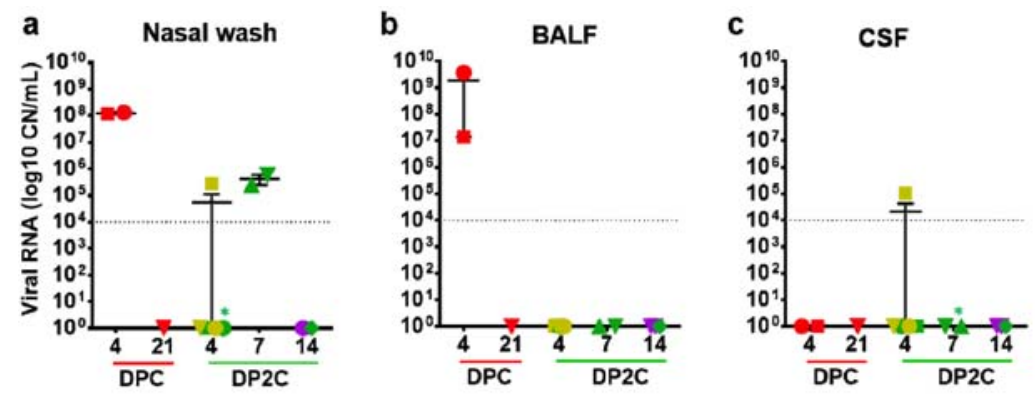

\begin{tabular}{|c|c|c|c|}
\hline Cat ID & Symbol & Necropsy & Treatment \\
\hline 328 & $\bar{\theta}$ & 4 DP2C & \multirow{3}{*}{$\begin{array}{c}\text { Study } 1 \\
\text { Re-infected }\end{array}$} \\
\hline 272 & $\bar{\nabla}$ & $4 \mathrm{DP} 2 \mathrm{C}$ & \\
\hline 903 & 무 & 4 DP2C & \\
\hline 305 & - & $4 \mathrm{DPC}$ & \multirow{3}{*}{$\begin{array}{c}\text { Study } 2 \\
\text { Principal } \\
\text { infected }\end{array}$} \\
\hline 526 & 口 & 4 DPC & \\
\hline 160 & $\nabla$ & $21 \mathrm{DPC}$ & \\
\hline 135 & - & 4 DP2C & \multirow{5}{*}{$\begin{array}{c}\text { Study } 2 \\
\text { Re-infected }\end{array}$} \\
\hline 590 & 口 & 4 DP2C & \\
\hline 247 & $\nabla$ & $7 \mathrm{DP} 2 \mathrm{C}$ & \\
\hline 119 & $\Delta$ & $7 \mathrm{DP} 2 \mathrm{C}$ & \\
\hline 127 & 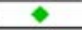 & 14 DP2C & \\
\hline 280 & 은 & $14 \mathrm{DP} 2 \mathrm{C}$ & \multirow{2}{*}{$\begin{array}{c}\text { Study 2 } \\
\text { Re-infection } \\
\text { Sentinels }\end{array}$} \\
\hline 620 & $\square$ & $14 \mathrm{DP} 2 \mathrm{C}$ & \\
\hline
\end{tabular}
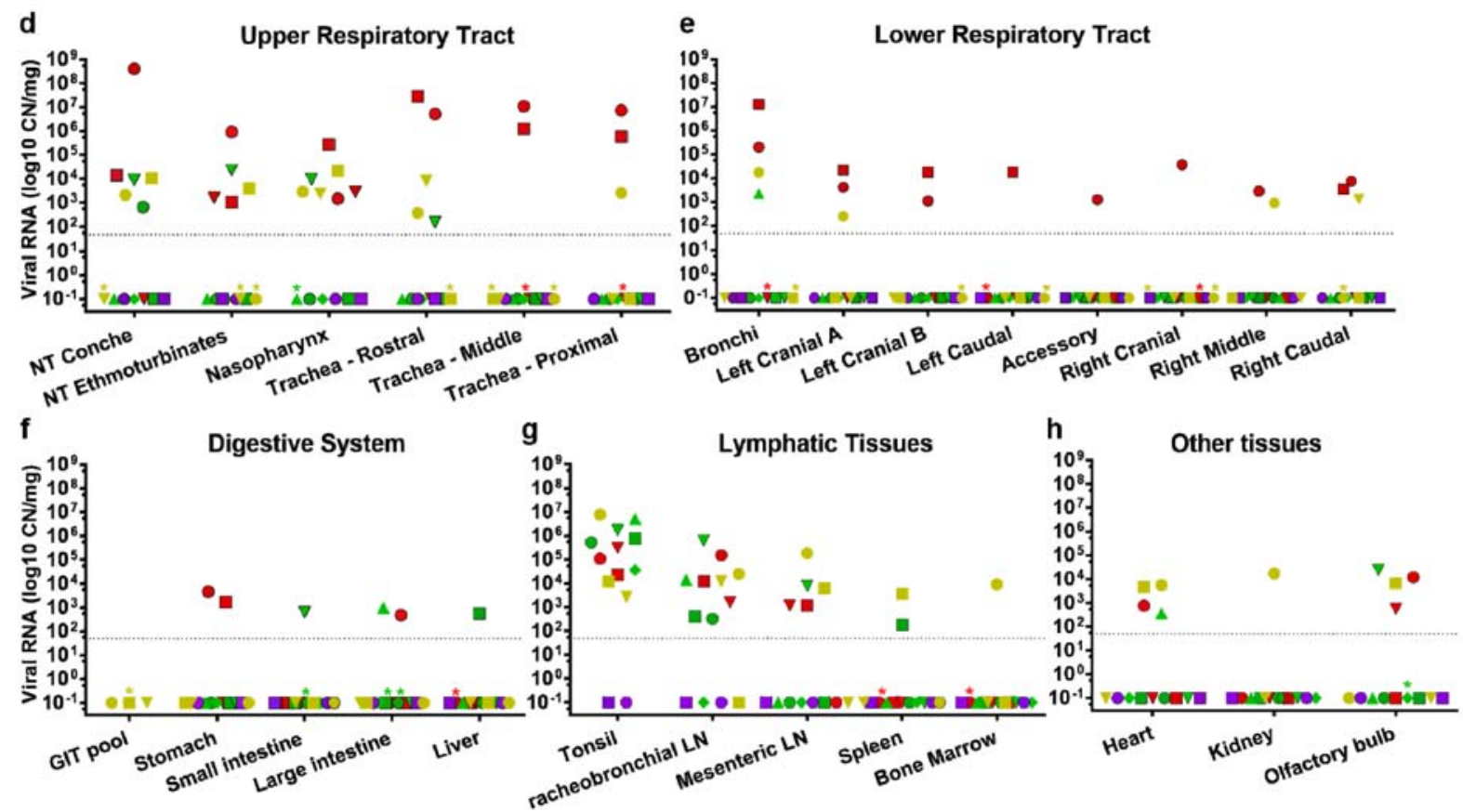

Figure 3. SARS-CoV-2 RNA detected in various tissues from infected and re-infected cats. RT-qPCR was used to detect the presence of SARS-CoV-2 in various tissues of cats euthanized at the indicated days after primary challenge (DPC) and re-challenge (DP2C). Viral RNA copy number $(\mathrm{CN})$ per $\mathrm{mL}(\mathrm{a}-\mathrm{c})$ or $\mathrm{mg}(\mathrm{d}-\mathrm{h})$ based on the nucleocapsid gene are plotted for individual animals. Coloured symbols corresponding to cat ID numbers, day of necropsy and study are indicated in the figure key. Asterisks $(*)$ indicate samples with 1 out of 2 of the RT-qPCR reactions below the limit of detection (LOD) which is, indicated by the dotted line.

of minimal to mild neutrophilic rhinitis (particularly on rostral and intermediate turbinates) at 4 DP2C, this was not as intense as that observed at 4 DPC. In all re-infected cats (4, 7 and 14 DP2C), multiple lymphoid aggregates were noted in the nasal passages similar to those noted at 21 DPC (Figure 6). No alterations within the respiratory mucosa (other than occasional transmigrating lymphocytes) and olfactory neuroepithelium were noted in nearly all re-infected animals. In a single cat from the second study (\#5904 DP2C), few neutrophils infiltrated a localized area of the olfactory neuroepithelium. No viral antigen or RNA were detected in the nasal cavity at any timepoint following re-infection (Figure 6). In the trachea and bronchi of re-infected cats, there was no evidence of tracheobronchoadentitis as noted at 4 DPC, and no viral antigen or RNA detected. Mild numbers of lymphocytes and plasma cells infiltrated tracheal and bronchial glands, and frequently formed lymphoid aggregates along the bronchial tree, interpreted as hyperplastic bronchial-associated lymphoid tissue (BALT, Figure 6).
While no significant histologic alterations were evident in the pulmonary parenchyma of primary infected cats and most of the re-infected cats (5/8), a localized area of reparative alveolitis was identified in a single bronchopulmonary segment in re-infected cats from the second study: \#590 (4 DP2C), \#119 (7 DP2C) and \#127 (14 DP2C). The affected area was characterized by early (\#590) to florid (\#119 and \#127) alveolar type 2 cell hyperplasia with few infiltrating mononuclear cells (lymphocytes and histiocytes) and small amounts of sloughed cell debris. No SARS-CoV-2 antigen or RNA were detected in the affected area or elsewhere in the pulmonary parenchyma (data not shown). No histologic changes in extrapulmonary organs were observed other than lymphoid hyperplasia within lymphoid organs.

\section{Re-infected cats do not transmit SARS-CoV-2 to sentinels}

In the second re-infection study, two sentinel SARSCoV-2 antibody-negative contact cats were 
(a)

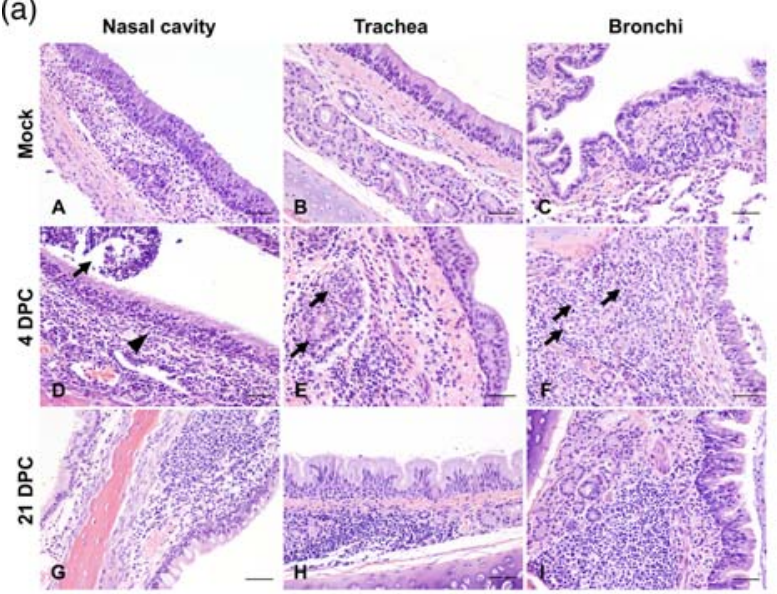

(b)

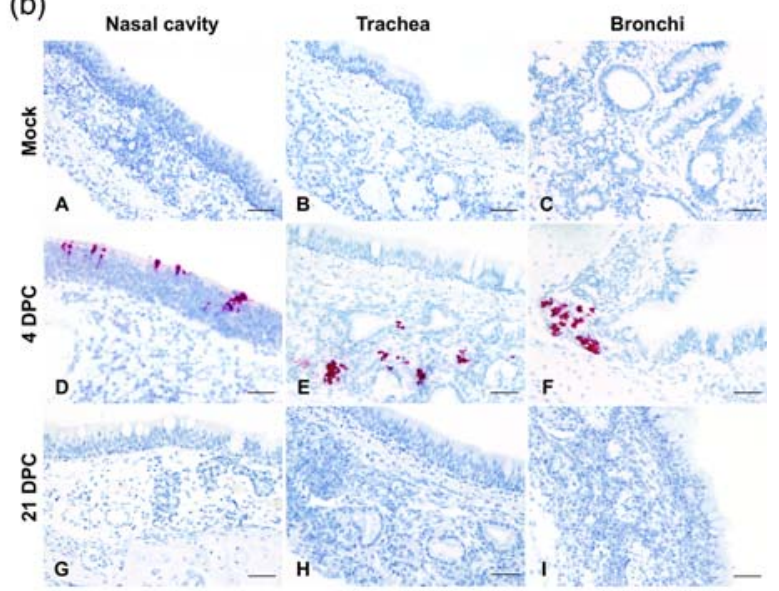

(c)

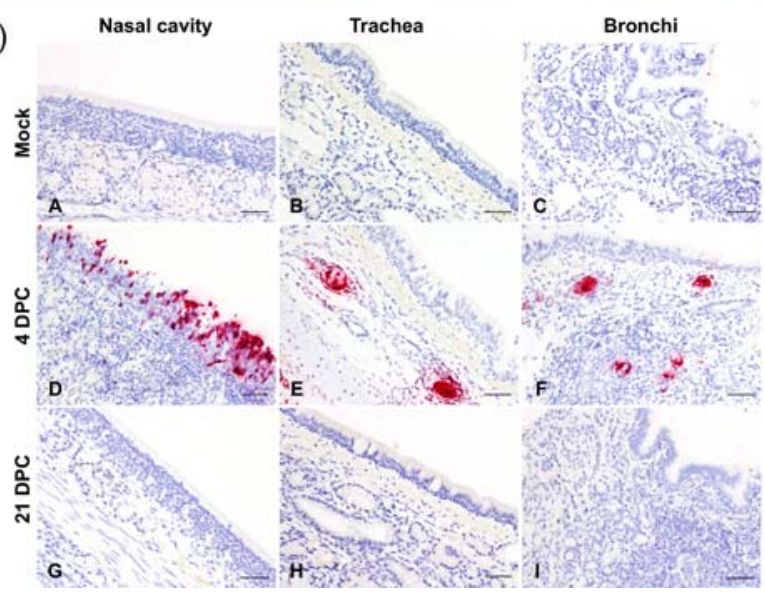

Figure 4. (a) Histologic lesions in the respiratory tract of primary infected cats. Mock-infected (A-C), 4 (D-F), and 21 days postchallenge (DPC; G-I) with SARS-CoV-2. At 4 DPC, intense neutrophilic rhinitis with luminal exudate (D, arrowhead and arrow, respectively) and lymphohistiocytic and neutrophilic tracheobronchoadenitis with necrosis and obliteration of seromucinous glands (E and F, arrows) were characteristic. At 21 DPC, histologic changes were limited to lymphoid aggregates in the lamina propria of the nasal turbinates $(\mathrm{G})$, trachea $(\mathrm{H})$ and bronchi $(\mathrm{I})$. H\&E, 200x total magnification. Bar $=100 \mu \mathrm{m}$. (b). SARS-CoV-2 distribution as determined by in situ hybridization in the respiratory tract of primary infected cats. Mock-infected (A-C), 4 (D-F), and 21 DPC (G-I) with SARS-CoV-2. At 4DPC, SARS-CoV-2 RNA was detected and localized within the nasal respiratory epithelium, olfactory neuroepithelium (D) and tracheobronchial glands in trachea and bronchi (E and F). At 21 DPC, no viral RNA was detected in the respiratory tract (G-I). Fast Red, 200x total magnification. Bar $=100 \mu \mathrm{m}$. (c). SARS-CoV-2 distribution as determined by immunohistochemistry in the respiratory tract of primary infected cats. Mock-infected (A-C), 4 (D-F), and 21 DPC (G-I) with SARS-CoV-2. At 4DPC, SARS-CoV-2 antigen was present in the nasal respiratory epithelium, olfactory neuroepithelium (D) and tracheobronchial glands in trachea and bronchi (E and F), co-localizing with viral RNA. At 21 DPC, no viral antigen was detected in the respiratory tract $(\mathrm{G}-\mathrm{I})$. Fast Red, $200 \times$ total magnification. Bar $=100 \mu \mathrm{m}$.

introduced and co-mingled with the re-challenged cats at $1 \mathrm{DP} 2 \mathrm{C}$ in order to determine if virus transmission occurrs following re-infection. The sentinels introduced after re-infection had temperatures slightly above $39^{\circ} \mathrm{C}$ at $2-4$ DP2C but were otherwise within normal range and remained asymptomatic up to 14 DP2C (supplemental figure 1). No viral shedding from nasal, oropharyngeal and rectal cavities was observed in these animals (Figure $2(\mathrm{a}-\mathrm{c})$ ) and no viral RNA was detected in tissues from either of the sentinel cats examined at 14 DP2C (Figure 3). Furthermore, the naïve sentinel cats co-housed with the reinfected cats for 13 days after re-challenge did not seroconvert (Table 2). Histologic evaluation of the nasal cavity identified multiple lymphoid aggregates similar to those noted in cats at 21 DPC and following reinfection with SARS-CoV-2. Minimal infiltrating lymphocytes and plasma cells along with sporadic lymphoid aggregates were noted in the submucosa along the bronchial tree, with no histologic changes in the pulmonary parenchyma. Viral antigen and RNA were not detected in tissues from sentinel cats.

\section{Discussion}

Knowledge of SARS-CoV-2 viral evolution, immunology and the longevity of immune protection against re-infection is still limited. Cases of SARSCoV-2 re-infections in humans have been recently reported [20-26]. Although the reported cases are relatively few, the true percentage and frequency of SARS-CoV-2 re-infections remain unclear. Furthermore, the outcome of a re-infection in terms of clinical disease and transmission is still not clearly 


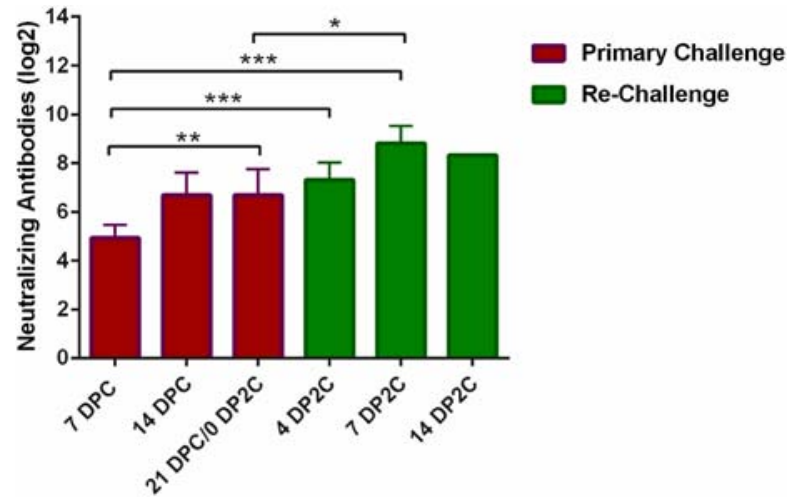

Figure 5. Virus neutralizing antibody responses in primary infected and re-challenged cats. Statistical analysis of virus neutralizing antibody titers were determined by multiple $\mathrm{t}$ test using the Holm-Sidak method, with alpha $=5.000 \%$. Only data for a single re-infected cat was available at 14 DP2C therefore significance could not be calculated. Statistical significance is indicated by: ${ }^{*}<0.05 ;{ }^{* *}<0.005 ;{ }^{* * *}<0.0005$; DPC $=$ days post primary challenge; $\mathrm{DP} 2 \mathrm{C}=$ days post second challenge

understood. While identifying and characterizing reinfection in humans naturally infected or vaccinated and re-exposed to SARS-CoV-2 remains important, studies using susceptible animal models allow for more systematic, in-depth investigations which can provide insight into SARS-CoV-2 re-infections in humans. Therefore, we investigated experimental reinfection in domestic cats as well as transmission following re-infection with SARS-CoV-2.

Based on our previous results from primary SARSCoV-2 infection in cats [12] and BSL-3Ag room scheduling constraints, cats were re-challenged at 21 DPC for these studies. Our results indicate that a primary SARS-CoV-2 infection was mostly resolved within 21 DPC. At 21 DPC, viral RNA shedding had subsided in the nasal and rectal cavities (Figure 2), no viral RNA or antigen were detected in the upper and lower respiratory tract with the exception of nasal turbinate, and nasopharynx homogenates (Figures 3 and 4). In addition, the histologic changes seen at early stages of infection (i.e. 4 and 7 DPC), characterized by intense neutrophilic rhinitis and tracheobronchoadenitis with necrosis of seromucinous glands of the trachea and bronchi, had completely resolved with only occasional lymphoid aggregates present along segmental bronchi. Following re-challenge, our results indicate that cats were at least partially protected from re-infection. All cats had circulating neutralizing antibodies at the time of rechallenge (Table 2), and viral RNA was detected from fewer tissues and at lower levels in the reinfected cats compared to primary infected cats examined at the same day after virus challenge (12; Figures 2 and 3). In our first re-infection study, viral RNA was detected in nasal washes, the URT and some LRT tissues of the three re-infected cats examined at 4 DP2C, suggesting that limited infection mainly in the URT might occur after SARS-CoV-2 rechallenge. Interestingly, in our second study, nasal washes, URT and GIT tissues of the two cats examined at 7 DP2C but not at 4 DP2C were RNA positive; this might suggest that the viral RNA detected in the URT and GIT may not be residual viral RNA from the SARS-CoV-2 challenge but replicating virus following re-challenge. Limited viral RNA shedding was also detected from nasal and rectal cavities up to $4 \mathrm{DP} 2 \mathrm{C}$ and oropharyngeal swabs up to 11 DP2C. The difference in RNA presence at 4 DP2C between the two studies could be related to the age of the cats (5 versus 7 months) and/or variation of responses among individual animals. Nonetheless, no viable virus was isolated from the swab samples of the re-infected cats, and the two sentinel contact cats co-housed with the re-challenged cats for 13 days remained SARS-CoV-2 negative and did not seroconvert. Therefore, re-challenged animals either did not shed viable virus or shed virus at insufficient levels for transmission to sentinels.

Interestingly, re-infected cats did not develop intense neutrophilic rhinitis or acute inflammation and necrosis targeting tracheobronchial glands when compared to primary infected cats at $4 \mathrm{DPC}$, and no viral antigen or RNA was detected within respiratory tract tissues following re-infection. The lymphoid aggregates frequently noted within the nasal passages and throughout the bronchial tree of re-infected cats resemble hyperplastic nasal and bronchi-associated lymphoid tissue (NALT and BALT), most likely a non-specific change following exposure to airborne pathogens. Whether this change represents a specific host immune response that either remained following the initial exposure to SARS-CoV-2 and expanded following re-exposure is unclear, since similar lymphoid clusters, albeit at lower frequency, were noted in the sentinel cats and in one of the mock-infected cats included in our first infection study [12]. A larger sample size and/or additional animals necropsied at 25,28 or 35 days after primary challenge would be necessary in order to confidently determine the frequency and distribution of this histopathological finding. However, due to BSL-3Ag room and housing constraints, including additional animals for these studies was not possible.

An additional and unexpected histologic lesion when compared to primary infected cats corresponded to the focal reparative alveolitis in three of the re-challenged cats. Unfortunately, the association of this histologic change with SARS-CoV-2 re-infection cannot be unequivocally confirmed. However, its association with SARS-CoV-2 infection is unlikely due to several reasons: (1) SARS-CoV-2 does not show a specific tropism for feline bronchial, bronchiolar or alveolar epithelial cells [12]; (2) no viral antigen 
(a)

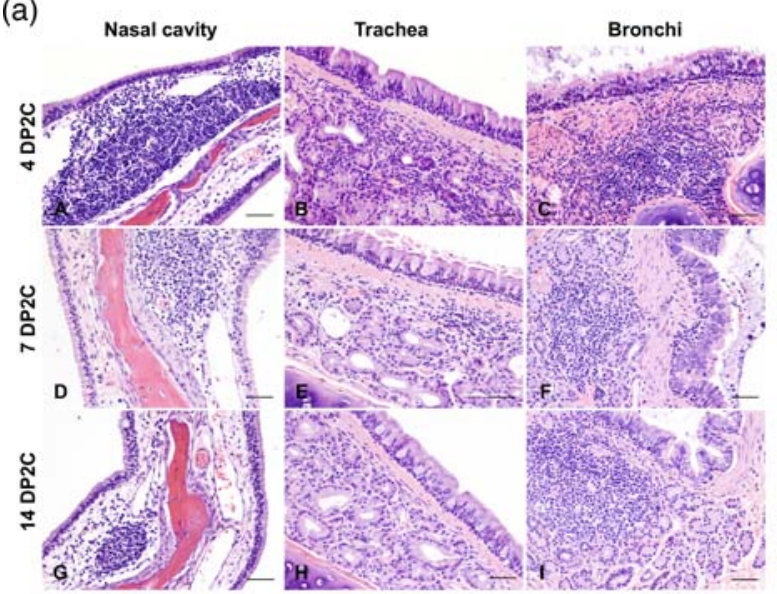

(b)

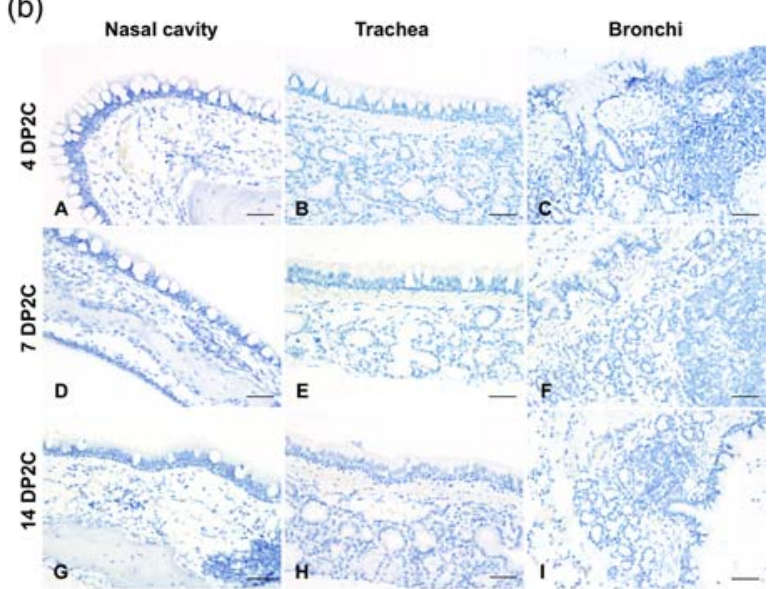

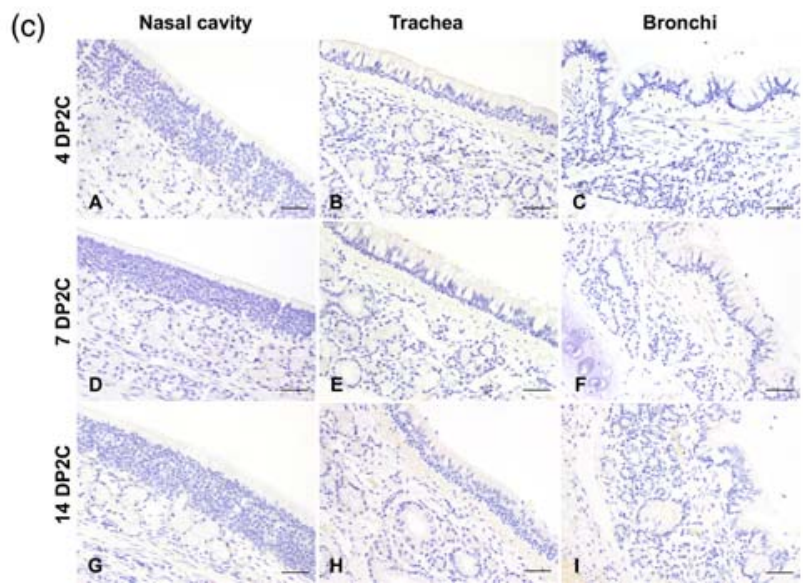

Figure 6. (a) Histologic lesions in the respiratory tract of re-challenged cats. 4 (A-C), 7 (D-F), and 14 days post second challenge (DP2C; G-I) with SARS-CoV-2. At all time points, variable lymphoid aggregates expanded the lamina propria of the nasal turbinates $(A, D, G)$, trachea $(B, E, H)$ and bronchi $(C, F, I)$. No disruption of tracheobronchial glands was noted. $H \& E$, $200 \times$ total magnification. $\mathrm{Bar}=100 \mu \mathrm{m}$. (b) SARS-CoV-2 distribution as determined by in situ hybridization in the respiratory tract of re-challenged cats. 4 $(A-C), 7(D-F)$, and 14 DP2C (G-I) with SARS-CoV-2. No viral RNA was detected in the nasal cavity $(A, D, G)$, trachea $(B, E, H)$ or bronchi $(C, F, I)$ at any time point. Fast Red, $200 \times$ total magnification. Bar $=100 \mu \mathrm{m}$. (c) SARS-CoV-2 distribution as determined by immunohistochemistry in the respiratory tract of re-challenged cats. 4 (A-C), 7 (D-F), and 14 DP2C (G-I) with SARS-CoV-2. No viral antigen was detected in the nasal cavity $(A, D, G)$, trachea $(B, E, H)$ or bronchi $(C, F, I)$ at any time point. Fast Red, 200× total magnification. Bar $=100 \mu \mathrm{m}$.

(by IHC) or viral RNA (via ISH and RT-qPCR) were detected within these lesions; (3) histologic changes suggestive of alveolar injury and repair were regional and not generalized and were not associated with clinical signs of disease; (4) the alveolar lesions were not present in all re-challenged cats. Other possible causes such as immune-mediated responses or inhaled antigens from the inoculum or environment should be considered. Additional experiments with a larger sample size are warranted to further investigate the mechanisms of immune protection from SARS-CoV2 and the development of pulmonary immunity in cats. Taken together, these results indicate that experimental re-infection of cats with SARS-CoV-2 results in partial protection from re-infection with limited infection primarily of the URT and GIT that was resolved by 14 DP2C; regardless, re-challenged animals either did not shed viable virus or shed virus at insufficient levels for efficient transmission to sentinels.
Other SARS-CoV-2 re-infection studies in cats, ferrets and rhesus macaques also showed at least partial to full protection from re-exposure at 4 weeks after primary challenge [27-29]. In a study by BoscoLauth and colleagues [15], three adult cats 5-8 years of age were experimentally infected with SARS-CoV2 and re-challenged 28 days later. In that study, no nasal or oral shedding of virus was observed during the 7 days after re-challenge and it was concluded that the animals were resistant to SARS-CoV-2 reinfection [15]. In our studies, we also did not detect infectious virus but did detect viral RNA shedding. Similar to Bosco-Lauth et al., we also observed a marked increase in neutralizing antibodies following SARS-CoV-2 re-challenge, suggestive of an anamnestic immune response. Similar results to ours were obtained in re-infection studies with non-human primates (NHPs) by two different groups [28,29]. After the initial SARS-CoV-2 clearance, animals were rechallenged with SARS-CoV-2 and showed significant 
reductions in viral loads in bronchoalveolar lavage and nasal mucosa when compared to the primary infection $[28,29]$. Anamnestic immune responses after re-challenge suggested that protection was mediated by immunologic control. The authors concluded that SARS-CoV-2 infection in rhesus macaques led to SARS-CoV-2 specific immune responses and provided protection against re-challenge. The residual levels of subgenomic mRNA in nasal swabs and the anamnestic immune response after SARS-CoV-2 re-challenge suggest that protection was mediated by immunologic control but was not sterilizing [28]. While these studies indicate that SARS-CoV-2 infection induces immune responses that provide at least some protection against re-infection in the short-term, the longevity of immune protection and the extent of crossprotection against divergent SARS-CoV-2 isolates that recently emerged, remain unclear.

Some insight into the longevity of immune responses and protection from re-infections might be derived from studies on similar coronaviruses. Studies on recovered patients infected with Severe Acute Respiratory Syndrome coronavirus (SARS$\mathrm{CoV}$ ) and Middle East Respiratory Syndrome coronavirus (MERS-CoV) indicate that virus-specific and neutralizing antibodies can persist for up to 2-3 years before significantly declining; still, protection against re-infection in such seropositive individuals is not known [30-36]. MERS-CoV re-infections in seropositive camels has been shown to occur $[37,38]$. A 35 year-long study investigating re-infections in individuals with seasonal human coronaviruses that typically result in minor disease found that re-infections occurred frequently around a year after the previous infection, indicating immunity is rather short-lived [39]. Further studies are needed to understand the long-term kinetics of immune responses to SARSCoV-2 and how these responses relate to protection from re-infection; and in cases of only partial protection, the risk of transmission and developing clinical disease. This work is also critical for determining the risk of companion animals as reservoirs for perpetuating the spread of SARS-CoV-2 and may also serve as a model to study SARS-CoV-2 immunity and re-infection in humans.

\section{Conclusions}

Here, we demonstrate that experimental SARS-CoV-2 infection in cats induces a protective immune response providing partial, non-sterilizing immune protection from re-infection. Furthermore, we show that re-infected cats did not shed virus at sufficient levels to infect co-housed, naïve animals. Future studies are aimed at understanding the longevity of immune protection against SARS-CoV-2. Nonetheless, these results suggest that immunological approaches to prevent and potentially treat SARS$\mathrm{CoV}-2$ are possible.

\section{Acknowledgements}

We thank the staff of KSU Biosecurity Research Institute, the histological laboratory at the Kansas State Veterinary Diagnostic Laboratory, the CMG staff and Sabarish Indran, Gleyder Roman-Sosa, Yonghai Li, and Emily Gilbert-Esparza at KSU. We also thank the staff at the Histology and Immunohistochemistry section of the Louisiana Animal Disease Diagnostic Laboratory (LADDL) for assistance with this study. The SARSCoV-2 strain USA-WA1/2020 was obtained through BEI Resources (catalogue \# NR-52281). Mention of trade names or commercial products in this publication is solely for the purpose of providing specific information and does not imply recommendation or endorsement by the US Department of Agriculture. USDA is an equal opportunity provider and employer.

\section{Disclosure statement}

No potential conflict of interest was reported by the authors.

\section{Funding}

Funding for this study was provided through grants from NBAF Transition Funds from the State of Kansas, the NIAID Centers of Excellence for Influenza Research and Surveillance under contract number HHSN 272201400006C, the National Institute of General Medical Sciences (NIGMS) of the National Institutes of Health under award number P20GM130448, and the Department of Homeland Security Center of Excellence for Emerging and Zoonotic Animal Diseases under grant number HSHQDC 16-A-B0006 to JAR. This study was also partially supported by the Louisiana State University, School of Veterinary Medicine start-up fund (PG 002165) to UBRB and the US Department of Agriculture, Agricultural Research Service (58-32000-009-00D) to WCW, by the Center for Research for Influenza Pathogenesis (CRIP), a NIAID supported Center of Excellence for Influenza Research and Surveillance (CEIRS, contract \# HHSN272201400008C), and by the generous support of the JPB Foundation, the Open Philanthropy Project (research grant 2020-215611 [5384]) and anonymous donors to AG-S.

\section{ORCID}

Velmurugan Balaraman (D) http://orcid.org/0000-00031671-5572

William C. Wilson (1) http://orcid.org/0000-0002-7877-9224 Juergen A. Richt (D) http://orcid.org/0000-0001-7308-5672

\section{References}

[1] Zhou P, Yang XL, Wang XG, et al. A pneumonia outbreak associated with a new coronavirus of probable bat origin. Nature. 2020;579(7798):270-273.

[2] Segales J, Puig M, Rodon J, et al. Detection of SARSCoV-2 in a cat owned by a COVID-19-affected patient in Spain. Proc Natl Acad Sci U S A. 2020;117 (40):24790-24793. 
[3] Neira V, Brito B, Agüero B, et al. A household case evidences shorter shedding of SARS-CoV-2 in naturally infected cats compared to their human owners. Emerg Microbes Infect. 2020;10:1-22.

[4] Hosie MJ, Epifano I, Herder V, et al. Respiratory disease in cats associated with human-to-cat transmission of SARS-CoV-2 in the UK. bioRxiv. 2020;2020.09.23.309948.

[5] Ruiz-Arrondo I, Portillo A, Palomar AM, et al. Detection of SARS-CoV-2 in pets living with COVID-19 owners diagnosed during the COVID-19 lockdown in Spain: a case of an asymptomatic cat with SARS-CoV-2 in Europe. Transbound Emerg Dis. 2020;00:1-4.

[6] Sit THC, Brackman CJ, Ip SM, et al. Infection of dogs with SARS-CoV-2. Nature. 2020;586(7831):776-778.

[7] Fritz M, Rosolen B, Krafft E, et al. High prevalence of SARS-CoV-2 antibodies in pets from COVID-19+ households. One Health. 2021;11:100192.

[8] Oreshkova N, Molenaar RJ, Vreman S, et al. SARSCoV-2 infection in farmed minks, the Netherlands, April and May 2020. Eurosurveillance. 2020 Jun;25 (23):2001005. doi: 10.2807/1560-7917.ES.2020.25.23. 2001005. PMID: 32553059; PMCID: PMC7403642.

[9] Hammer AS, Quaade ML, Rasmussen TB, et al. SARSCoV-2 transmission between mink (neovison vison) and humans, Denmark. Emerg Infect Dis. 2020;27(2) 547-551.

[10] Oude Munnink BB, Sikkema RS, Nieuwenhuijse DF, et al. Transmission of SARS-CoV-2 on mink farms between humans and mink and back to humans. Science. 2021;371(6525):172-177. doi: 10.1126/ science.abe5901. Epub 2020 Nov 10. PMID: 33172935; PMCID: PMC7857398.

[11] McNamara T, Richt JA, Glickman L. A critical needs assessment for research in companion animals and livestock following the pandemic of COVID-19 in humans. Vector Borne Zoonotic Dis. 2020;20 (6):393-405.

[12] Gaudreault NN, Trujillo JD, Carossino M, et al. SARSCoV-2 infection, disease and transmission in domestic cats. Emerg Microbes Infect. 2020;9(1):2322-2332.

[13] Shi J, Wen Z, Zhong G, et al. Susceptibility of ferrets, cats, dogs, and other domesticated animals to SARScoronavirus 2. Science. 2020;368(6494):1016-1020.

[14] Halfmann PJ, Hatta M, Chiba S, et al. Transmission of SARS-CoV-2 in domestic cats. N Engl J Med. 2020;383 (6):592-594.

[15] Bosco-Lauth AM, Hartwig AE, Porter SM, et al. Experimental infection of domestic dogs and cats with SARS-CoV-2: pathogenesis, transmission, and response to reexposure in cats. Proc Natl Acad Sci U S A. 2020;117(42):26382-26388.

[16] Zhang Q, Zhang H, Gao J, et al. A serological survey of SARS-CoV-2 in cat in Wuhan. Emerg Microbes Infect. 2020;9(1):2013-2019.

[17] Stevanovic V, Vilibic-Cavlek T, Tabain I, et al. Seroprevalence of SARS-CoV-2 infection among pet animals in Croatia and potential public health impact. Transbound Emerg Dis. 2020 Nov 15:10.1111/ tbed.13924. doi: 10.1111/tbed.13924. Epub ahead of print. PMID: 33191649; PMCID: PMC7753394.

[18] Lu X, Wang L, Sakthivel SK, et al. US CDC real-time reverse transcription PCR panel for detection of severe acute respiratory Syndrome coronavirus 2. Emerg Infect Dis. 2020;26(8):1654-1665.
[19] Carossino M, Ip HS, Richt JA, et al. Detection of SARS-CoV-2 by RNAscope in situ hybridization and immunohistochemistry techniques. Arch Virol. 2020;165(10):2373-2377.

[20] Goldman JD, Wang K, Roltgen K, et al. Reinfection with SARS-CoV-2 and failure of humoral immunity: a case report. medRxiv [Preprint]. 2020 Sep 25:2020.09.22.20192443. doi: 10.1101/2020.09.22. 20192443. PMID: 32995830; PMCID: PMC7523175.

[21] To KK, Hung IF, Ip JD, et al. COVID-19 re-infection by a phylogenetically distinct SARS-coronavirus- 2 strain confirmed by whole genome sequencing. Clin Infect Dis. 2020 Aug 25. pii: 5897019. doi: 10.1093/ cid/ciaa1275.

[22] Tillett RL, Sevinsky JR, Hartley PD, et al. Genomic evidence for reinfection with SARS-CoV-2: a case study. Lancet Infect Dis. 2020;21:52-58.

[23] Van Elslande J, Vermeersch P, Vandervoort K, et al. Symptomatic SARS-CoV-2 reinfection by a phylogenetically distinct strain. Clin Infect Dis. 2020 Sep 5. pii: 5901661. doi: 10.1093/cid/ciaa1330.

[24] Prado-Vivar B, Becerra-Wong M, Guadalupe JJ, et al. A case of SARS-CoV-2 reinfection in Ecuador. Lancet Infect Dis. 2020 Nov 23. pii: S1473-3099(20)30910-5. doi: 10.1016/S1473-3099(20)30910-5.

[25] Gupta V, Bhoyar RC, Jain A, et al. Asymptomatic reinfection in two healthcare workers from India with genetically distinct SARS-CoV-2. Clin Infect Dis. 2020;Sep 23:ciaa1451. doi: 10.1093/cid/ciaa1451. Epub ahead of print. PMID: 32964927; PMCID: PMC7543380.

[26] Gidari A, Nofri M, Saccarelli L, et al. Is recurrence possible in coronavirus disease 2019 (COVID-19)? case series and systematic review of literature. Eur J Clin Microbiol Infect Dis. 2020 Oct 10:1-12. doi: 10. 1007/s10096-020-04057-6.

[27] Cameron MJ, Kelvin AA, Leon AJ, et al. Lack of innate interferon responses during SARS coronavirus infection in a vaccination and reinfection ferret model. PLoS One. 2012;7(9):e45842. doi: 10.1371/journal. pone.0045842. Epub 2012 Sep 24.

[28] Chandrashekar A, Liu J, Martinot AJ, et al. SARS$\mathrm{CoV}-2$ infection protects against rechallenge in rhesus macaques. Science. 2020;369(6505):812-817.

[29] Deng W, Bao L, Liu J, et al. Primary exposure to SARSCoV-2 protects against reinfection in rhesus macaques. Science. 2020;369(6505):818-823.

[30] Liu W, Fontanet A, Zhang PH, et al. Two-year prospective study of the humoral immune response of patients with severe acute respiratory syndrome. J Infect Dis. 2006;193(6):792-795.

[31] Mo H, Zeng G, Ren X, et al. Longitudinal profile of antibodies against SARS-coronavirus in SARS patients and their clinical significance. Respirology. 2006;11 (1):49-53.

[32] Wu LP, Wang NC, Chang YH, et al. Duration of antibody responses after severe acute respiratory syndrome. Emerg Infect Dis. 2007;13(10):1562-1564.

[33] Cao WC, Liu W, Zhang PH, et al. Disappearance of antibodies to SARS-associated coronavirus after recovery. N Engl J Med. 2007;357(11):1162-1163.

[34] Tang F, Quan Y, Xin ZT, et al. Lack of peripheral memory B cell responses in recovered patients with severe acute respiratory syndrome: a six-year follow-up study. J Immunol. 2011;186(12):72647268 . 
[35] Choe PG, Perera R, Park WB, et al. MERS-CoV antibody responses 1 year after symptom onset, South Korea, 2015. Emerg Infect Dis. 2017;23 (7):1079-1084.

[36] Payne DC, Iblan I, Rha B, et al. Persistence of antibodies against Middle East Respiratory Syndrome coronavirus. Emerg Infect Dis. 2016;22(10):1824-1826.

[37] Ali MA, Shehata MM, Gomaa MR, et al. Systematic, active surveillance for Middle East Respiratory
Syndrome coronavirus in camels in Egypt. Emerg Microbes Infect. 2017;6(1):1-7.

[38] Hemida MG, Alnaeem A, Chu DK, et al. Longitudinal study of Middle East Respiratory Syndrome coronavirus infection in dromedary camel herds in Saudi Arabia, 2014-2015. Emerg Microbes Infect. 2017;6(6):e56.

[39] Edridge AWD, Kaczorowska J, Hoste ACR, et al. Seasonal coronavirus protective immunity is shortlasting. Nat Med. 2020;26(11):1691-1693. 